\title{
Mean Carbon Monoxide Diffusing Capability Test
}

National Cancer Institute

\section{Source}

National Cancer Institute. Mean Carbon Monoxide Diffusing Capability Test. NCI

Thesaurus. Code C123564.

The mean volume of the carbon monoxide that is transferred from inspired gas into the pulmonary capillary blood. 